\title{
Emergence Unites Ecology and Society
}

\author{
$\underline{\text { Ronald L. Trosper }}^{1}$
}

\begin{abstract}
The effort to combine analysis of ecosystems and social systems requires a firm theoretical basis. When humans are present in an ecosystem, their actions affect emergent structures; this paper examines forms of emergence that account for the presence of humans. Humans monitor and regulate ecosystems based on their cultural systems. Cultural systems consist of concepts linked in complicated ways that can form consistent world views, can contain inconsistencies, and may or may not accurately model the properties of a social-ecological system. Consequently, human monitoring and regulating processes will differ, depending on cultural systems. Humans, as agents, change or maintain pre-existing material and cultural emergent structures. The presentation is illustrated with a case study of fire-prone forests. The paper shows that explicit attention to emergence serves very well in unifying the following requirements for social-ecological analysis: coherent and observable definitions of sustainability; ways to link ecological and social phenomena; ways to understand cultural reasons for stability and instability in dynamic social-ecological systems; and ways to include human self-evaluation and culture within dynamic models of social-ecological systems. Analysis of cultural emergent structures clarifies many differences in assumptions among the fields of economics, sociology, political science, ecology, and ecological economics. Because it can be readily applied to empirical questions, the framework provides a good way to organize policy analysis that is not dominated by one or another discipline.
\end{abstract}

Key Words: analytical dualism; complexity; critical realism; ecological economics; emergence; socialecological systems; sustainability

\section{INTRODUCTION}

This journal addresses the intersection of ecology and society; such an effort needs a sound theoretical basis. This paper presents a proposed basis for uniting analysis of ecology and society through use of emergent structures and their properties. Emergence has received attention for more than a century, with an upsurge recently in ecology, sociology, and biology. This paper begins with a review of concepts of emergence, and then continues by using distinctions among types of emergence provided by sociologist Margaret Archer (1995, 1996, 2000, 2003). The result is a framework that provides excellent guidance for combining ecology and sociology, hence for uniting analysis of ecosystems and social systems.
After laying out the resulting framework, the paper argues that it shows great promise for analysis of social-ecological systems. This point is supported by a case study of changed ideas about fire in forests of ponderosa pine (Pinus ponderosa $\mathrm{P}$. Laws. ex $\mathrm{C}$. Laws.). A framework should pass tests to show its usefulness. The final section of the paper applies the following six tests of the framework: to provide a definition and explanation of sustainability; to place humans solidly within social-ecological systems; to bridge the disciplines involved; to facilitate dynamic analysis; to address specific topic areas in ecological economics; and to provide policy analysis. This proposed framework passes the tests. 


\section{EMERGENCE}

This section reviews emergent structures and their properties. It ends with a combination of types of emergence that is relevant and useful for analysis of social-ecological systems. A large literature describes various ways to characterize emergence and the resulting stratification. Beckerman (1992), Blitz (1992), and Stephan (1992) all provide reviews of the literature; Bunge $(1979,2004)$ and Bhaskar $(1975,1979,1986)$ present recent, thorough treatments. Cunningham (2000) provides a taxonomy of types of emergence. Baas (1994a, 1994b, 1996) presents a definition of emergence that relies upon observational mechanisms, a narrow definition not used by other authors.

In the conclusion of his survey of emergence, Blitz (1992) distinguishes among a system $a$ made up of a set of parts, $C(a)$, relationships among the parts, $\left\{r_{1}, \ldots, r_{\mathrm{n}}\right\}$, and the properties both of the parts and of the system:

A certain configuration of parts, or component configuration, is always associated with each emergent property. In the simplest case, this thesis states that an emergent property $q$ of a system $a$ is associated with some relation $r$ between components $y_{1}$ and $y_{2}$ in $C(a)$. In a more complicated and realistic case, there would be associated with each emergent property $q$ a set of relations $r_{1}$ through $r_{\mathrm{n}}$ holding between members of a subset of $C(a)$. A component configuration is invariably associated with every emergent property of a thing. Emergent properties are anchored in structures, and do not exist independently of them, though they are not reducible to them. (Blitz 1992, p. 179)

Each emergent property and the system (or structure) that creates it occurs in a wider context involving the environment around the system, which Blitz (1992) denotes $E(a)$, and interactions between the system and its environment also affect emergent properties. Yet the environment is not part of $a$. Other authors, such as Bunge $(1979,2004)$, include $E(a)$ in the definition of the system $a$. Cunningham (2000) includes this distinction in his taxonomy: some emergent properties arise through internal relationships; others arise through external relationships.

Because the emergent property $q$ is a property of $a$ and is not a property of any component $y$ in $C(a)$, emergent properties are novel. This characteristic provides a test for emergence: if the properties of $a$ are also properties of components $C(a)$, then emergence has not occurred. Instead, the situation is a case of a mere summation of the parts, a quantitative feature, because more of a property remains the same property. Although Cunningham (2000) includes examples of aggregation as a type of emergence, usually aggregate properties are not classified as emergent properties.

Powers are among the emergent properties of an emergent structure. When the relationships among the parts are strong enough, the resulting emergent structure has the power to influence other structures, and also to affect its constituent parts. This aspect of emergence makes it useful. Such powers also are controversial; Kim (1992) argues against emergent structures being able to influence component parts and Humphries (1997) argues the opposite. Humphries wins the argument that such "downward causation" is possible.

Once one has defined a structure with emergent properties, one can easily generalize to sets of structures, each of which is composed of structures. Higher levels are often called systems. Such a stratification has different names, each of which carries connotations some authors dislike. For instance, Bunge (1979, p. 14) prefers "levels" because "hierarchy" implies dominance. Gunderson and Holling (2002) prefer "panarchy" because they see lower levels affecting higher levels and higher levels affecting lower levels. Some assert that causation can only go "up" or "down." The term "stratified ontology" imposes fewer assumptions on the stratification. Using "ontology" emphasizes the nature of what is being studied, rather than knowledge about the object of study. Examples of such stratifications have been presented for both ecosystems and social systems. Allen and Hoekstra (1992) survey the types of hierarchy that exist in ecological theory. Both Archer (1995, 1996, 2000, 2003) and Weissman (2000) explicitly use a stratified ontology for analysis of social systems. Salthe $(1985,1993)$ provides many biological examples, along with classification of hierarchy types.

Given this general framework, further analysis can be accomplished by examining types of emergence, based upon the types of components that make up the set $C(a)$ and the types of relationships that are in the set $\left\{r_{1}, \ldots, r_{\mathrm{n}}\right\}$. As many possibilities exist, one can imagine a fairly elaborate list of types of 
emergence.

First, examine the components. If the contents of $C$ (a) are ideas, concepts, and values, then attention applies to types of cultural emergence. If the contents of $C(a)$ are material, then types of material emergence are under examination. Among material items, one can distinguish humans, and have types of purely people's structures. Archer $(1995,1996)$ distinguishes among these three types. It is also possible to examine mixed instances of emergence, where the components are not all of one type. Of special importance are emergent structures that depend on both ideas and material relationships.

Second, examine the relationships. If the contents of $C(a)$ are ideas, then the relationships are logical: the ideas can be consistent with one another, they can contradict each other, or they can have no logical relationship. If the contents of $C(a)$ are material things, many types of relationships are possible: physical connection, exchange of materials, participation in processes. The exchanges may be only internal to the system, or external relationships may also have to be considered. People's structures typically have roles, each with responsibilities, obligations, titles, and duties to other humans in the structure. Roles have varying amounts of power.

Whether or not emergent structures and emergent properties exist has generated considerable heat in the philosophy of science. One of the main issues is this: should emergence be defined in terms of whether or not humans understand it, or do emergent structures have an existence independent of human knowledge? Because the philosophical debate has important implications for the modeling of humanity's roles in ecosystems, it deserves close examination. Roy Bhaskar has labeled the claim that emergence does not occur without human understanding as the "epistemic fallacy:"

This consists in the view that statements about being can be reduced to or be analysed in terms of statements about knowledge; i.e. that ontological questions can always be transposed into epistemological terms. (Bhaskar 1975, p. 36)

Bhaskar is right, some philosophers insist that emergence must be defined in terms of knowledge. The widely cited definition by Broad (1925, p. 61), for instance, requires that emergent properties be non-deductible, an epistemological requirement. In his survey of types of emergence, Cunningham
(2000) includes a definition that does not include knowledge. He claims, however, that such examples involve "mythic" factors, and concludes the article with a graph in which complex phenomena fall into a category called "epistemically emergent," hence knowledge dependent.

Bhaskar (1975) criticizes descriptions of being that always involve use of human knowledge. Two other positions are possible: being is always independent of human knowledge, and being sometimes incorporates human knowledge and sometimes does not. This paper takes the third position. When humans are involved in an emergent structure, the knowledge of those humans matters, because it affects what humans do. But other influences are also important; humans exist in a material world.

The knowledge of people inside an emergent structure affects the structure, and thus human knowledge becomes part of the system's relationships. This is the case whether or not the knowledge in question accurately models the system. People's intended outcomes may or may not be the outcomes that occur.

The study of social-ecological systems needs to include ways to examine human knowledge. One way to do this is to classify types of human intervention in an ecosystem on a scale from low intervention to high intervention. Examples of small interactions are observation and monitoring. Examples of intermediate interventions are harvesting the annual net increase in a population, or changing the timing of processes already existing in a system, such as causing fires in cool weather rather than hot weather. High intervention involves adding or removing species or processes from an ecosystem. Extreme intervention consists of totally replacing one ecosystem with another, as when a city fully occupies an area that previously had no city.

\section{Analysis of Dynamics within Systems of Emergent Structures}

Distinguishing among material, cultural, and people's emergent structures provides a way to describe change in dynamic systems with significant control by humans. Imagine a system of structures that includes humans. Humans are constrained and enabled by existing emergent structures. Humans also have the power to change 
those structures by acting as agents. Other emergent structures can also affect change, by creating limitations or creating opportunities. Dynamic analysis proceeds by clearly delineating emergent structures, their powers, and the efforts of humans and other agents to act within the constraints and opportunities offered by the configuration of emergent structures.

To discuss dynamics, one needs to define agents, the emergent entities who argue about ideas, operate or influence material emergent structures, and reorganize themselves. Archer (1995, 2000) distinguishes between "primary agents" and "corporate agents." Primary agents are people in similar circumstances without influence on either material or cultural emergent structures. Corporate agents are groups of people who have the ability to modify emergent structures, which includes the emergence of "agency" itself. This division of people into passive participants and movers and shakers is rejected by many social theorists, including many economists, but plays a key analytical role for Archer. Her third book on the critical realist approach to social theory examines human agency in detail (Archer 2000).

In order to obtain analytical purchase on complicated problems, one needs an approach that separates each of the factors, yet allows one to tell plausible stories about the dynamics that result. In this effort, a four-step procedure recommended by Archer (1995) for use in sociology should be extended to analysis of social-ecological systems. Here is a brief description of her recommended procedure:

- Prior to applying the procedure, one needs to tentatively adopt a set of periods, distinguished by times of stability and times of change. Starting with the end of a period of stability, the first step is to identify the emergent structures of all three types that are in place. These cultural, material, and people's structures set the stage for subsequent change. Repeated application of the test that each higher level has emergent properties allows identification of the relevant stratified ontology.
- The second step is to identify the potentialities created by the emergent structures. Patterns of complementarities and contradictions are particularly important. Complementarities, unless challenged, promote stability; contradictions, when not controlled, promote instability. If a system is dominated by complementarities, change may be difficult and perpetuation of current patterns is the most likely outcome. If the system is dominated by contradictions, change is likely but the outcomes are highly uncertain.

- Completion of steps one and two is preparation for consideration of the next period, that of change. Step three is the description and analysis of the actions of agents. Humans, in particular, organized into groups, take action. These actions affect emergent structures, including the organizations of humans. Non-humans also act, often in ways not predicted by humans, and the consequences affect what humans attempt to do. Humans experience surprise when actions are not what were expected.

- Step four is analysis of the new configuration of emergent structures that results from the actions of agents within the constraints and opportunities that had been offered by the old configuration of emergent structures. Completion of step four sets the stage for analysis of subsequent events, by proceeding back to step one.

\section{Analysis of Cultural Structures}

In order to examine human knowledge as part of an emergent structure, namely a complex ontology of a social-ecological system, one needs a few tools for describing cultural systems. Archer (1995) provides such tools. Cultural structures consist of sets of ideas that have internal and necessary relationships; these relationships form the emergent properties of the structures. The logical relationships can be either complementarity or contradiction. In Culture and Agency, Archer (1996) provides stimulating and relatively exhaustive 
consideration of the impact of systemic configurations of ideas upon the choices offered to agents who are operating within the opportunities presented by those systemic configurations.

A necessary contradiction occurs when an idea A calls forth a contradictory idea $B$, and the two cannot be separated. In natural resource management, "sustained yield" is a necessary contradiction, in which idea A, yield, is inextricably linked to a separate idea, "sustained," and the two contradict one another. In the American forestry sector, deployment of "multiple-use sustained yield" created a multiply contradictory idea, because each use of the forest was supposed to be sustained, and any one could come to dominate. Because it could neutralize opponents by appearing to grant their wishes, the policy of multiple-use sustained yield successfully left the agents desiring high timber harvest in charge from 1945 to the 1990s (Trosper 2003a). "Sustainable development" is also such a necessary contradiction, as Robinson (2004) explains.

A contingent contradiction occurs when idea $\mathrm{A}$ and idea B are contradictory, but not necessarily related to each other. This condition can be reached in cases of necessary contradiction by reversal of roles. If idea B becomes separated from idea A, as occurs when "ecosystem management" replaces "sustained" in the sustained yield idea, it is then possible for the idea of timber harvest to become separate and not necessarily related to ecosystem management (Cortner and Moote 1999, chapter 3).

A necessary complementarity exists when idea A calls forth idea B, and the two are consistent with one another. For instance, the ideas used in neoclassical economics for construction of consumer theory and welfare economics have a necessary and internal complementary relationship to the ideas of utilitarianism, because neoclassical economics in its current form includes basic assumptions of utilitarianism. Mirrlees (1982) and Hammond (1982) have spelled out the connection explicitly, as have others in the book with their essays (Sen and Williams 1982). Hammond, for instance, maintains that "the whole study of welfare economics is founded more or less explicitly on utilitarian ideas, even when economists deal only with the idea of Pareto efficiency-when no individual can be made better off without making someone else worse off" (Hammond 1982, p. 85). Because of this complementarity, dissatisfaction with utilitarian ethics leads to dissatisfaction with neoclassical economics.

A contingent complementarity exists when there is no necessary relationship between $\mathrm{A}$ and $\mathrm{B}$, but the ideas are consistent with one another. Ideas used in the study of chemistry probably have no inconsistency with ideas in the study of literature. This paper explores possible contingent complementarities among different uses of emergence.

Archer (1995) insists on a fundamental distinction, that between the "cultural system" and "sociocultural interaction." The difference "maps on to that between culture without a knowing subject and culture with a knowing subject" (Archer 1995, p. 180). People use ideas, create ideas, and argue about them. Those processes are sociocultural interaction, and create emergence. Once created and published (however that is done), the ideas can be separated from those who know them. The cultural system is the realm of ideas, a gigantic library of them, which is available only by combining all of the world's great libraries with all of the knowledge held outside of the libraries. Just as a hammer exists separate from the carpenter, the central limit theorem exists separate from the statistician, and the two fundamental theorems of welfare economics exist separate from economists.

The power of a cultural emergent property, such as the complementary relationship between utilitarianism and economics, becomes a cause when human agents use the logical relationships to justify actions. For instance, for many years, any attempt to publish an introductory textbook in economics, without using utilitarianism to describe consumer theory, would not have survived peer review.

Archer (1996) points out that each of the four possibilities creates particular logical relationships that constrain agents when trying to use the ideas. When dealing with a necessary contradiction, for example, the advocates of idea A have to keep idea B contained, because it threatens the hegemony of idea A. When dealing with a necessary complementarity, agents can work hard to reinforce that complementarity.

The implications for sociocultural interaction are quite interesting, and Archer $(1995,1996)$ lays them out in her book. For the purposes of socialecological analysis, the case of the treatment of signals from an ecosystem to a set of social actors 
illustrates the importance of distinguishing types of cultural system configurations. The receptiveness of corporate agents to information from ecosystems will differ in the different configurations of the cultural system. Table 1 lays out the proposed relationships.

As shown in Table 1, the configuration of a necessary contradiction leads to suppression of signals that trouble may be brewing. Holling and Meffe (1986) spell out how this happens in some detail, as does Walters (1997) in considering the obstacles that prevent adoption of adaptive management by natural resource agencies devoted to ideas of sustained yield.

In contrast, when a community undertakes ecosystem restoration, after a period of excessive resource use, all members of the community can see an increase in the delivery of ecosystem services. Restoration creates complementary benefits, not allocation of tradeoffs between alternatives. The existence of recognized necessary complementarity explains the rapid and public adoption of ecosystem monitoring in such situations. Configurations in the cultural system affect the effectiveness of monitoring processes, which in turn will affect intervention actions.

\section{CASE STUDY: FIRE IN PINE-DOMINATED FOREST ECOSYSTEMS}

Examination of a complex problem, that of the role of fire in ponderosa pine-dominated ecosystems in the American West illustrates the usefulness of distinguishing types of emergence. Current dilemmas in the reconciliation of the desire of people to live in forests that are prone to catastrophic fire have arisen from the history of fire management in those forests. A recent book surveys the ecological, economic, social, and political context of restoring the forests (Friederici 2003). Explicit attention to emergent structures and their properties presents a useful way to organize the available information to generate additional insights. First, application of the test for emergence provides a way to identify structures with power to both constrain and enable agents. Second, agents have a choice of operating within the given constraints, or changing them. Third, in order for agents to change the emergent structures, agents must change the interactions that have created the emergent properties. Thus, the positions agents take as they struggle over policy can be understood in the context of their roles in supporting or opposing emergent structures. Alliances among agents can be similarly understood; sometimes allies are surprising because of the logic of emergent cultural structures. The key material structures in this story are the forests and the presence or absence of a wood-processing industry. The key cultural structures are ideas about fire, which connect to scientific concepts and to the human role in ecosystems. The key people's structures are federal agencies, nongovernmental organizations, local governments, business groups, scientists, and the alliances that they form.

In this case, the emergent property of concern is vulnerability to catastrophic wildfires; fires so large and powerful that no human efforts can stop them. This danger exists because humans suppressed fire for more than a century. One method was indirect: the use of cattle and sheep to consume the grasses that provided fuel for frequent ground fires. A second was direct: extinguishment of all forest fires upon ignition. As a result of these actions, trees increased in numbers, creating more standing fuel - fuel ladders to the canopy - and increased litter under the trees (Covington et al. 1994). When the fires burned housing subdivisions, the danger became very important politically for cities in the American Southwest.

The fire vulnerability of the ponderosa pine forest was caused by fire suppression activities that resulted from emergent structures of the American political and economic system, which in turn came into existence as the West was settled in the late $19^{\text {th }}$ century. The ponderosa pine forests in the presettlement period consisted of stands of sparsely distributed old trees in grasslands that experienced frequent fires fueled by dry grass. The thick bark of the ponderosa pine protected it from fire. The timing of the fires in some areas was natural, caused by lightning in the summer; in others, it was anthropogenic, caused by indigenous peoples burning the landscape in cool seasons. Just before European settlement, the density of indigenous population decreased as epidemics of communicable diseases wiped out up to $90 \%$ of them. The European settlers found a landscape with abundant grass, large trees, and a few Indians who were easily confined to reservations.

The settlers were at the periphery of an expanding industrial economy. The use of steam engines for 
Table 1. Effects of cultural system configurations on ecosystem monitoring

\begin{tabular}{ll}
\hline \hline Cultural System Configuration & Clarity of Ecosystem Signal Receipt \\
\hline Necessary contradiction & Suppression of signals that reveal the contradiction. \\
Contingent contradiction & $\begin{array}{l}\text { Each side uses data to support its position; but each critiques } \\
\text { the other; no suppression but reluctance to accept the other's } \\
\text { views. Dominance of one side will lead to suppression of } \\
\text { other views; until that occurs, much information will be } \\
\text { forthcoming. }\end{array}$
\end{tabular}

Necessary complementarity

Comfortable solidarity will lead to suppression of signals that contradict the complementarity, but other signals provide no threat and may be encouraged. Links among complementary ideas are stressed.

Contingent complementarity

Different approaches coexist with no reason to engage one another; each approach gathers the data that support it. No reason exists to gather data on interactions.

power dominated the economy, and railroads were important in establishing the new population in the West. Both the abundant grasses and large trees presented opportunities for the settlers. The grasses supported a period of grazing cattle, the forests provided timber - and both were shipped eastward to support the expanding industrial economy. After the grasses had been cleared by the cattle, good seed years established dense stands of ponderosa pine. Whether or not the presettlement structure would return depended on the settlers' approach to fire management.

In the late $19^{\text {th }}$ century, government officials and forest scientists in the United States had not as yet adopted fire suppression, although they were leaning in that direction. At that time, the United States was a highly racist society, and in particular, the indigenous peoples were depicted as ignorant savages. When John Wesley Powell advocated the use of fire in managing forests, his proposal was derisively described by his opponents as "Paiute forestry," even though "light fire" was widely used by non-Indians as well (Pyne 1997, pages 100-122; Lewis 2002). The complementarity of racist beliefs and indigenous practices weakened the ability of Powell and his allies to defend the wisdom of indigenous practices. The emergent property of racism in America at a national scale gave a powerful tool to one side of the debate in a small sector, forestry. In addition to the factor of racism, Powell's defeat occurred because timber was valuable for harvest, and the forestry profession was interested in establishing its authority over managed forests. Because widespread technical advances legitimized the idea that man could dominate nature, those who assumed that fire could be handled through fire suppression activities won the debate.

In subsequent decades, new material and people's emergent structures developed. The Forest Service promised to control fire, and did so for many decades. After World War II, the Forest Service also provided timber to industrial forest concerns. This provided lumber for a surge of housing construction. An emergent material structure arose in the economy as the forest sector provided a flow of wood fiber to the growing cities. This structure complemented an emergent people's structure, an "iron triangle" at the national level consisting of an alliance between the U.S. Forest Service, Congressional committees, and timber business interests. This alliance used the idea of "multipleuse sustained yield" to provide lip service to provision of many products while timber dominated (Trosper 2003a).

Because conquering fire was a key component for the reputation of technical forestry, any proposal that fire was good met fierce resistance. Forest Service scientists documenting the value of fire in managing longleaf pine found they could not disseminate results easily (Schiff 1962). Once the image was invented after World War II, the power 
of Smokey the Bear blocked other ideas. For instance, in the mid $20^{\text {th }}$ century, Omer Stewart (2002) was unable to publish a book on the subject of aboriginal burning (Lewis and Anderson 2002, Lewis 2002). An indigenous forester in charge of fire management in a US national forest tried to let hunter-set fall fires burn in a pine forest in Idaho, but when the Regional Forester flew over, the order to put out all fires by $10 \mathrm{a} . \mathrm{m}$. was enforced (Trosper n.d.).

The internally contradictory policy of multiple-use sustained yield had required considerable effort to contain the contrary ideas of "sustained" and "multiple use" while "yield of timber" dominated. Ecological conditions, which contradicted major parts of the official stand, finally overthrew the containment strategy in several ways. One such way was the need to protect endangered species, required by the Endangered Species Act and the regulations enforcing the National Forest Management Act. Another was catastrophic fire that destroyed homes; the Los Alamos fires were the most publicized.

Because the forests had become unhealthy, potentially subject to catastrophic fire and to insect epidemics, complementary interests developed at local levels in the American Southwest, even as the overthrow of sustained-yield theories created competing interests at the national level. The local complementarities are among cities and towns wishing to have fire protection; conservation biologists, restoration ecologists, and local environmentalists desiring restored ecosystems; and businessmen wanting to make use of abundant wood fiber. These local interests argue that removing fuel from the forest is cheaper than fighting catastrophic fire. The complementarities create a strong interest in monitoring. Monitoring is especially necessary, because new plant species are present; these plants may inhibit restoration of the old symbiosis between grass and pine. (These points are explored in the articles in Friederici (2003).) The fact that aboriginal people had burned in this manner was rediscovered, even if it was not accepted by everyone (Boyd 1999, Vale 2002). Stewart's book was, at last, published (Stewart 2002).

But at the national level, contradictions remain as a legacy of the power of the iron triangle. Having successfully almost halted national forest harvest in the Pacific Northwest, national environmental organizations oppose anything that might allow the previous alliance to return. This includes opposition to use of wood fiber in the Southwest. To date, their efforts have only served to delay action; interest group alliances in places like Flagstaff, Arizona, and Montezuma County, Colorado, have started largescale fuel reduction programs, and have reinstituted light fire. Some leaders in the U. S. Forest Service are trying to forge a new alliance with these local interests, but others are trying to return to the previous alliance with industry.

Just as occurred when the policy of fire suppression was adopted, a struggle exists because national emergent structures are different from local ones. Necessary complementarity typifies local issues, and contingent contradictions typify national issues. In the first struggle, the desire to suppress fire that had received strength in 1910 because of fires in Idaho in the Northwest prevented adoption of prescribed fire in the South and Southwest. In the current struggle, the desire to prevent development of new sawlog harvesting in the Northwest threatens to prevent thinning of forests in the Southwest. That forests are diverse is a point that national political dynamics seem unable to accommodate; either fire is good or it is bad, or timber harvest is good or bad.

Another type of forest structure is going to emerge as a consequence of the current crisis. Understanding the process of change can be helped by identifying the emergent structures and examining the choices that human agents make in the context of those structures. Predicting the outcome is difficult.

\section{TESTS OF THE FRAMEWORK}

Above, I have presented a definition of emergent structures of three types: material, cultural, and people's. I have shown how such structures are stratified, and how emergent properties exist at several levels. Emergent cultural structures can affect material structures through human action. The case of ponderosa pine illustrates how changes in emergent structures result from human action, and in turn cause humans to respond. Now, I turn to the six tests of a framework presented at the start of the paper. The tests are as follows: (1) to provide a definition and explanation of sustainability; (2) to place humans solidly within social-ecological systems; (3) to bridge the disciplines involved; (4) to provide analysis of dynamics; (5) to deal with specific areas of enquiry in ecological economics; 
and (6) to provide policy analysis. Although other tests can be proposed, any framework that does well on these six is a promising approach.

\section{Sustainability Definitions}

Full sustainability for a social-ecological system is maintenance of emergent structures of all three kinds: material, cultural, and people's. Partial sustainability would be stasis in only one or two types of structure, or sustainability in all three types in one sector of society. Questions arise: Is partial sustainability of any type truly sustainable? How can a combination of change in some structures be reconciled with lack of change in others?

Many concepts of ecological sustainability describe unchanging material structures. Strong sustainability, for instance, means that material structures such as the use of ecosystem services remain unchanged (Ekins et al. 2003). Such sustainability could accompany changes in other spheres; an open question is whether or not it would require stasis in other emergent structures. Daly (1991) proposes that "development" be used in the sense of intensification of material use without changing the rate of throughput in a social-ecological system. This type of change would require steady change in cultural structures (technology). That change may or may not be consistent with steady throughput.

"Weak" sustainability involves keeping the incomeproducing capability of capital stock in nondeclining mode. Changes in some material structures must occur, as human-made capital substitutes for natural capital. To observe such sustainability would require monitoring mechanisms to verify income-producing capability. In addition, cultural change, technology again, would be needed to create the human-made capital that replaces the natural capital.

As society becomes interested in sustainability in either the strong or weak sense, one would expect that monitoring mechanisms would be developed to observe the status of ecosystem services, whether produced with a constant natural capital stock or with a combination of human-made and natural capital. Communities are defining criteria and indicators for sustainability in either sense. This is consistent with the idea that observation and monitoring mechanisms matter in development of new emergent properties.
Archer's analysis of cultural structures alerts analysts to examine relationships among ideas to discern contradictions and complementarities. The idea of "sustainable development" is a candidate for Archer's (1996) "necessary contradiction" category, because the ordinary meaning of development is "growth," which cannot continue forever on a finite planet. The Brundtland Report (World Commission on Environment and Development 1987) connects sustainable development to a change in the distribution of income, where relatively poor people become richer. This suggests that change in material, cultural, and people's emergent structures would need to accompany sustainable development in the Brundtland sense. Sustainability defined in a way that requires changing emergent structures is not consistent with constancy in those structures. The approach advocated here raises a key question for Brundtland-type sustainability: how is it sustained in the presence of change in all emergent structures? This puzzle has been noted before; see Robinson (2004) for a summary_although he does not use emergent structures as used here.

A widespread view is that the current trajectories of many industrial economies seem to be unsustainable. If this is true, then detailed examination of emergent structures should reveal the reasons for the lack of sustainabilty. Consideration of all three types of structures should alert analysts to the necessity of examining cultural and people's structures in the process of examining material structural relationships. Those who advocate study of social memory and learning (Berkes and Folke 1998, 2002, Folke et al. 2003) should consider how patterns of contradictions and complementarities in the cultural system help or inhibit memory and learning. Analysis of emergent structures and properties, and the dynamics of agency, draws attention to reproduction of emergent structures as the process that provides sustainability.

\section{Incorporation of Humans}

This paper's framework places humans firmly in the analysis, through explicit attention to cultural systems. Humanity's knowledge engages ecosystems through monitoring, regulating, and managing emergent structures that incorporate human activity. Not only does one reject the separation of man and nature, one includes man in the system through people's activities, through emergent 
corporate agents, and through conceptual systems. The case of fire management shows that conceptual systems affect material emergent structures; in that case, when the idea to exclude fire triumphed over ideas that resident peoples had used in vegetation management. The resulting cultural pattern resisted change for nearly a century, until overwhelming evidence caused the old ideas to gain new acceptance.

\section{Bridging Disciplines}

This approach both bridges and challenges the disciplines. The four steps of analysis described above allow one to describe ways in which particular disciplines or sub-disciplines tend to oversimplify the analysis in ways that are similar across disciplines. Some disciplines focus on structures, leaving agents to adjust; others focus on agents, ignoring the impact of structures in the formation of agents. A full theory requires both. As a first step in dealing with the disparate approaches of economics, ecology, history, literature, political science, and sociology, one asks of them: in what ways do they assume simplifications in this very complex interaction of material and cultural structures that are manipulated and changed by people's structures through corporate agency?

Margaret Archer (especially 1995, pages 169-172, and 2003, pages 9-16) assists in this comparison of disciplines by pointing out several varieties of "conflation"- - ways in which the relevance of one or more of the four steps in the analysis is actively denied. Steps one and two involve analysis of emergent structures and the constraints they impose. The fields of cultural studies, sociology, and systems ecology are strong in describing emergent structures, but are weak in describing processes of change. Economics, evolutionary biology, public choice theory, and psychology are primarily focused on the interaction of agents, the analysis of step three. These fields don't much want to hear about structures that limit or channel change. Their analysis, therefore, is helpful in studying mechanisms of change, and is of less help in studying what inhibits change.

Because students enrolled in courses that seek to combine ecology, economics, political science, and sociology typically come from a variety of fields, this process of classifying the fields according to the particular simplifications those fields prefer tends to liberate students from the socialization processes in each discipline. Encouraging careful consideration of the ontological assumptions of each of the disciplines excels as a first step to building bridges between them. One has to know where the banks are in order to construct a bridge. This approach also encourages dispassionate analysis of the complementarities and contradictions among the disciplines, presenting ways to understand why certain concepts or data are consistently ignored or denied.

The exercise does not have to be entirely negative, because many fields do explicitly recognize and study emergent structures. Policy analysis examines policy regimes (Sabatier 1999a, 1999b); ecology describes hierarchies and food webs (Allen and Hoekstra 1992, Peterson and Parker 1998); economists talk about path dependence and the difficulties of defining equilibrium (Arthur 1994, Arrow 1994, Stiglitz 2002); group selection is recognized by some evolutionary theorists (Sober and Wilson 1998, Tooby and Cosmides 1992). Those focused on downward causation are great at identifying emergent structures; those focused on upward causation are great at identifying how agents act. By setting aside restrictions on upward and downward causation, one can use the strengths of each discipline to provide unified explanations.

\section{Addressing Dynamics}

By clearly distinguishing three types of emergence, Archer $(1995,1996,2000,2003)$ provides analysts with ways to categorize and study material, cultural, and people's emergent properties. She places agency at the center of analyzing change and dynamics: how do agents by their actions either reproduce existing cultural and material structures, or change them? What are the existing cultural and material structures, and how do they limit or expand the choices available to particular agents?

Most social-ecological models focus on material relationships, without sufficient attention to cultural issues. Systemic patterns among ideas affects the ability of humans to understand material relationships and to learn about them, particularly when nonhuman components are causing change. Humans also cause change.

A major difficulty in dynamic analysis is dealing with unpredictable events; the presence of human 
agency strongly contributes to uncertainty. Although both cultural and material structures affect agents, agents have choices and could make ones different from those they choose. Some of the decisions reshape cultural emergent structures; others change material emergent structures. Once those structures are modified, new opportunities and limits come into existence to condition the actions of agents. Explicit recognition that human agency will remain unpredictable is helpful.

\section{Addressing Major Topics in Ecological Economics}

This test is presented because I teach a course in ecological economics. In my course, I begin with an extensive introduction to the ideas of emergence given above, followed by presentation of the contrasting approaches to the management of salmon fisheries (Trosper 2002, 2003b). The salmon case study introduces some of the topics important in ecological economics, such as sustainability, common property systems, environmental ethics, and resource governance. The rest of the course treats emergent structures in this order: material, cultural, people's.

The main topics that fit into material structures are material definitions of sustainability (the majority of such definitions), input-output analysis extended to include flow of materials into and out of ecosystems (Jin et al. 2003), types of capital (Ekins 2003), and types of ecosystem services (Daily 1997). Types of capital and types of ecosystem services are of course tightly linked as components of separate emergent structures (de Groot et al. 2002, Ekins 2003, Ekins et al. 2003). "Capital" is a structure because it emerges out of relationships, among many things. I end the section with consideration of the adaptive cycle as a dynamic approach to consideration of material structures, in its panarchy form (Holling 2001, Gunderson and Holling 2002). Discussion focuses on adding cultural structures to the adaptive cycle.

Issues of valuation provide a transition from material structures to cultural structures. Brown (1984) provides a good introduction to the hierarchical structures of values, and also a way to introduce demand curves in a general framework, without assuming utilitarianism. The different observation mechanisms of standard national income accounting and green accounting provide another way to examine the importance of cultural structures in defining the observational mechanisms that affect material structures (Costanza et al. 2001, England 2001).

Joseph Stiglitz's (2002) work emphasizes the tenuous nature of "equilibrium" as an emergent structure in neoclassical economics: if different participants in a market have different information - which is a result of pre-existing cultural and material structures - then observed prices may be far from "pareto optimal" prices. Explicit attention to observation and monitoring mechanisms explains why different participants have different information. If one recognizes a stratified ontology, then one readily accepts the possibility that higher level agents, governments in Stiglitz's examples, need to intervene when lower levels fail.

After covering valuation, I use Ostrom's work in institutional analysis to introduce the hierarchy of rules that are used to structure human decision making (Ostrom 1990, 1999, 2001, Crawford and Ostrom 1995, Gibson et al. 2000). Constitutions, policy regimes, public choice arenas are all important manifestations of strong cultural structures that influence social-ecological systems. Although types of goods (private, club, public, and common pool) are defined in the section on ecosystem services, this distinction needs to be recalled in the analysis of governing systems (Burger et al. 2001).

Analysis of people's emergent properties incorporates firms, households, and governments in the analysis. Assisting analysis of people's emergent structures are the models of man that are the current subject of research using experimental economics (Gintis 2000, ch. 11).

I end the course, by combining the analysis of agency (primary and corporate) with consideration of alternative policies. The development of international consensus and rules on dealing with ozone-depleting chemicals provides a nice case study to illustrate application of emergent structures to a policy arena (Parson 2003). With more time, most of the major policy proposals could be analyzed in the concluding section of the course. I cover how this is done in the next section. 


\section{Policy}

Policy is the enactment of cultural structures of particular force, with the intent of changing agents' behavior and modifying material structures. Implementation is the creation and perpetuation of the structures through monitoring, enforcement, and other forms of human action. The approach of this paper enhances theories of the policy process such as the Institutional Analysis and Development Framework (Ostrom 1999) and the Advocacy Coalition Framework (Sabatier and Jenkins-Smith 1999). The Institutional Analysis and Development framework is strong on analysis of rules and rule making (hence on cultural structures), but weak on social conditioning, because agents are modeled in the spirit of rational choice theory. Also, the distinction between primary and corporate agency is omitted. The Advocacy Coalition Framework is strong on describing corporate agency, but tends to operate within a largely implicit set of cultural structures. Both pay attention to material structures that limit agents' choices.

That theories and models can be used as ideologies -interpretations that legitimize existing power structures-can be seen as a part of any operating social-ecological system. Such ideologies have to be maintained by those operating the cultural monitoring mechanisms and, as such, can also be attacked by undermining the mechanisms.

Using the above definition of policy, I provide students with a blank table (see Table 2) delineating a series of descriptive matters that need to be identified in particular case studies. The students are to use the table in any policy analysis they undertake in papers for the course. The table helps students review the literature on a case, by classifying what is known about the case into the categories of material, cultural, and people's structures. In class, I select among policy proposals such as eco-labeling, tradable permits, emission taxes, performance bonds, and quotas.

\section{Summary of Tests}

The emergence framework presented in this paper passes all six tests, in some cases with distinction. It provides a thorough way to consider sustainability by including cultural structures and people's structures in addition to the usual material structures. Focusing on monitoring and regulation mechanisms presents an excellent way to include humans in the analysis. By distinguishing among types of emergent structures, and by focusing on agency as a source of change for such structures, the approach allows the ideas of different disciplines to be placed within a comprehensive framework. Dynamics in social-ecological systems can include the cultural system as well as the material system, although agent choices are hard to predict. Major issues in ecological economics can be dealt with in the framework. The full complications of policy analysis can be laid out, particularly with stress on the importance of cultural structures in such analysis.

\section{CONCLUSION}

This paper presents a survey of emergence, focusing particularly on the distinctions among cultural, material, and people's emergent structures. When humans are involved in the relationships that create emergent structures, the results depend on the knowledge held by humans, as well as on the instrumental goals those humans pursue. The resulting emergent properties may or may not be what the particular humans in question intended to create.

In the case of forest fires in ponderosa pine (or other fire-prone tree species), the emergence of a forest at high risk of catastrophic destruction occurs when fires of all types are suppressed over a long period of time. When fires are not suppressed, or when they are set at particular times and places, the resulting forest does not have the particular emergent property of vulnerability to catastrophic fire.

Recognition and use of emergence engages a large and contentious literature about the philosophy of science. This paper locates this definition within the philosophical debate about emergence, without engaging in more than a sketchy defense of the concepts used. Key to the defense is an insistence that acceptance of a stratified ontology means one does not assert either that all emergence can be understood in terms of human knowledge or that human understanding is always irrelevant. Humans have evolved with advanced cognitive abilities; to include them in ecosystem models, one must engage human knowledge systems. The world, however, existed before humans arrived and will survive should they disappear. 
Table 2. Template for policy analysis

Policy Recommendation

Material Structures/Emergent Properties (MS/EPs) Addressed: or Used:

How would these MS/EPs be changed?

Cultural Structures/Emergent Properties (CS/EPs) Addressed: or Used:

How are these CS/EPs changed by this policy?

People's Emergent Structures and Properties: 1. Which corporate agents are primarily responsible for maintenance of current emergent structures?

2. Which corporate agents are expected to carry out the changes recommended by this policy?

3. Who are the primary agents expected to respond to this policy in a helpful way? Will they? Did they?

Social Interaction: What struggles are occurring or will occur about the character of new material structures and their emergent properties? How are these struggles conditioned by contradictions and complementarities among existing structures?

Social-cultural Actions: What struggles are occurring or will occur about the character of new cultural emergent structures and properties? How are these struggles conditioned by contradictions and complementarities among existing structures?

Social Interaction, Socio-cultural Interaction and new People's Emergent Properties: What changes are occurring in the composition of corporate agents? Are new alliances or new organizations emerging? How are these changes conditioned by both material and cultural structures? How do they proceed to impact and change material and cultural structures?

Division into phases: What would be a helpful configuration of emergent structures to identify as the "initial conditions?" What are the dates of this configuration? What subsequent configurations are important as distinctive stages in the history of this policy arena? What would be a helpful configuration of emergent structures and properties to identify as the "the next outcome?" What are the dates of this configuration?

In the process of laying out the concepts of emergence, this paper discussed ways to compare different disciplinary and sub-disciplinary systems of concepts. These comparisons help bring knowledge taken from many disciplines to bear upon particular social-ecological structures. In doing this, the paper shows that a framework using emergence provides the following: (1) ways to classify various definitions of sustainability; (2) a way to place humans within ecological systems, rather than outside of them; (3) bridges between the disciplines involved in studying the phenomena of social-ecological systems; (4) a description of how agents create change, thus providing dynamic analysis; (5) a basis to organize study of ecological economics; and (6) a framework for analyzing the development of policy.

Responses to this article can be read online at:

http://www.ecologyandsociety.org/vollo/iss 1/art14/responses/

\section{Acknowledgments:}

I would like to thank my students in the two 
ecological economics courses at the School of Forestry, Northern Arizona University, for challenging discussions. I began this research with a grant from the Pew Fellowship in Conservation and the Environment. Comments from this journal's reviewers and editors were extremely helpful.

\section{LITERATURE CITED}

Allen, T. F. H., and T. W. Hoekstra. 1992. Toward a unified ecology. Columbia University Press, New York, New York, USA.

Archer, M. S. 1995. Realist social theory: the morphogenetic approach. Cambridge University Press, Cambridge, UK.

Archer, M. S. 1996. Culture and agency: the place of culture in social theory. Cambridge University Press, Cambridge, UK.

Archer, M. S. 2000. Being human: the problem of agency. Cambridge University Press, Cambridge, UK.

Archer, M. S. 2003. Structure, agency and the internal conversation. Cambridge University Press, Cambridge, UK.

Arrow, K. J. 1994. Methodological individualism and social knowledge. American Economic Review 84(2):1-9.

Arthur, W. B. 1994. Increasing returns and path dependence in the economy. University of Michigan Press, Ann Arbor, Michigan, USA.

Baas, N. A. 1994a. Emergence, hierarchies, and hyperstructures. Pages 515-537 in C. G. Langton, editor. Artificial life III, Santa Fe studies in the sciences of complexity, Proc. Volume XVII. Addison-Wesley, Redwood City, California, USA.

Baas, N. A.1994b. Hyper-structures as a tool in nanotechnology. Nanobiology 3:49-60.

Baas, N. A. 1996. A framework for higher order cognition and consciousness. Pages 633-648 in S. Hameroff, A. Kaszniak, and A. Scott, editors, Towards a science of consciousness. MIT Press,
Cambridge, Massachussetts, USA.

Beckermann, A. 1992. Introduction-reductive and nonreductive physicalism. Pages 1-21 in A. Beckermann, H. Flohr, and J. Kim, editors. Emergence or reduction? Essays on the prospects of nonreductive physicalism. Walter de Gruyter, New York, New York, USA.

Berkes, F. 2002. Back to the future: ecosystem dynamics and local knowledge. Pages 121-146 in L. H. Gunderson and C. S. Holling, editors. Panarchy: understanding transformations in human and natural systems. Island Press, Washington, D. C., USA. [See Erratum]

Berkes, F. and C. Folke, editors. 1998. Linking social and ecological systems: management practices and social mechanisms for building resilience. Cambridge University Press, Cambridge, UK.

Bhaskar, R. 1975. A realist theory of science. Leeds Books Ltd., Leeds, UK.

Bhaskar, R. 1979. The possibility of naturalism: a philosophical critique of the contemporary human sciences. Humanities Press Inc., Atlantic Highland, New Jersey, USA.

Bhaskar, R. 1986. Scientific realism and human emancipation. Verso, London, UK.

Blitz, D. 1992. Emergent evolution: qualitative novelty and the levels of reality. Kluwer Academic Publishers, Dordrecht, The Netherlands.

Boyd, R., editor. 1999. Indians, fire and the land in the Pacific Northwest. Oregon State University Press, Corvallis, Oregon, USA.

Broad, C.D. 1925. The mind and its place in nature. Routledge and Kegan Paul, Ltd., London, UK.

Brown, T. C. 1984. The concept of value in resource allocation. Land Economics 60:231-246.

Bunge, M. 1979. Ontology II: a world of systems. (Treatise on Basic Philosophy; Volume 4.) D. Reidel Publishing Company, Dordrecht, The Netherlands.

Bunge, M. 2004. Emergence and convergence: qualitative novelty and the unity of knowledge. 
University of Toronto Press, Toronto, Ontario, Canada.

Burger, J., E. Ostrom, R. B. Norgaard, D. Policansky, and B. D. Goldstein, editors. 2001. Protecting the commons: a framework for resource management in the Americas. Island Press, Washington, D.C., USA.

Cortner, H. J., and M.A. Moote. 1999. The politics of ecosystem management. Island Press, Washington, D.C., USA.

Costanza, R., S. Farber, B. Castaneda, and M. Grasso. 2001. Green national accounting: goals and methods. Pages 262-281 in C. J. Cleveland, D. I. Stern, and R. Costanza, editors. The economics of nature and the nature of economics. Edward Elgar Publishing, Cheltenham, UK.

Covington, W. W., R. L. Everett, R. W. Steele, L. I. Irwin, T. A. Daer, and A. N. D. Auclair. 1994. Historical and anticipated changes in forest ecosystems of the Inland West of the United States. Journal of Sustainable Forestry 2:13-63.

Crawford, S. E. S., and E. Ostrom. 1995. A grammar of institutions. American Political Science Review 89(3):582-600.

Cunningham, B. 2000. The reemergence of "emergence." Philosophy of Science 68:S62-S74.

Daily, G. C., editor. 1997. Nature's services: societal dependence on natural ecosystems. Island Press, Washington, D.C., USA.

Daly, H. E. 1991. Steady-state economics, second edition with new essays. Island Press, Washington, D.C., USA.

de Groot, R. S., M. A. Wilson, and R. M. J. Boumans. 2002. A typology for the classification, description and valuation of ecosystem functions, goods and services. Ecological Economics 41:393408.

Ekins, P. 2003. Identifying critical natural capital: conclusions about critical natural capital. Ecological Economics 44:277-292.

Ekins, P., S. Simon, L. Deutsch, C. Folke, and R. De Groot. 2003. A framework for the practical application of the concepts of critical natural capital and strong sustainability. Ecological Economics 44:165-185.

England, R. W. 2001. Alternatives to gross domestic product: a survey. Pages 218-237 in C. J. Cleveland, D. I. Stern, and R. Costanza, editors. The economics of nature and the nature of economics. Edward Elgar Publishing, Cheltenham, UK.

Folke, C., J. Colding, and F. Berkes. 2003. Synthesis: building resilience and adaptive capacity in social-ecological systems. Pages 352-387 in C. Folke, J. Colding, and F. Berkes, editors. Navigating social-ecological systems: building resilience for complexity and change. Cambridge University Press, Cambridge, UK.

Friederici, P., editor. 2003. Ecological restoration of southwestern ponderosa pine forests. Island Press, Washington, D.C., USA.

Gibson, C. C., E. Ostrom, and T. K. Ahn. 2000. The concept of scale and the human dimensions of global change: a survey. Ecological Economics 32:217-239.

Gintis, H. 2000. Game theory evolving: a problemcentered introduction to modeling strategic interaction. Princeton University Press, Princeton, New Jersey, USA.

Gunderson, L. H. and C.S. Holling, editors. 2002. Panarchy: understanding transformations in human and natural systems. Island Press, Washington, D. C., USA.

Hammond, P. J. 1982. Utilitarianism, uncertainty and information. Pages 85-102 in A. Sen and B. Williams, editors. Utilitarianism and beyond. Cambridge University Press, Cambridge, UK.

Holling, C. S. 2001. Understanding the complexity of economic, ecological, and social systems. Ecosystems 4:390-405.

Holling, C. S., and G. K. Meffe. 1986. Command and control and the pathology of natural resource management. Conservation Biology 10(2):328337.

Humphreys, P. 1997. How properties emerge. Philosophy of Science 64(1):1-17.

Jin, D., P. Hoagland, and T. M. Dalton. 2003. 
Linking economic and ecological models for a marine ecosystem. Ecological Economics 46:367385 .

Kim, J. 1992. "Downward causation" in emergentism and nonreductive physicalism. Pages 119-138 in A. Beckermann, H. Flohr, and J. Kim, editors. Emergence or reduction? Essays on the prospects of nonreductive physicalism. Walter de Gruyter, New York, New York, USA.

Lewis, H. T. 2002. An anthropological critique. Pages 17-36 in H. T. Lewis and M. K. Anderson, editors. Forgotten fires: Native Americans and the transient wilderness. University of Oklahoma Press, Norman, Oklahoma, USA.

Lewis, H. T., and M. K. Anderson. 2002. Introduction. Pages 3-16 in H. T. Lewis and M. K. Anderson, editors. Forgotten fires: Native Americans and the transient wilderness. University of Oklahoma Press, Norman, Oklahoma, USA.

Mirrlees, J. A. 1982. The economic uses of utilitarianism. Pages 63-84 in A. Sen and B. Williams, editors. Utilitarianism and beyond. Cambridge University Press, Cambridge, UK.

Ostrom, E. 1990. Governing the commons: the evolution of institutions for collective action. Cambridge University Press, Cambridge, UK.

Ostrom, E. 1999. Institutional rational choice: an assessment of the institutional analysis and development framework. Pages 35-71 in P. A. Sabatier, editor. Theories of the policy process: theoretical lenses on public policy. Westview Press, Boulder, Colorado, USA.

Ostrom, E. 2001. Reformulating the commons. Pages 17-41 in J. Burger, E. Ostrom, R. B. Norgaard, D. Policansky, and B. D. Goldstein, editors. Protecting the commons: a framework for resource management in the Americas. Island Press, Washington, D.C., USA.

Parson, E. A. 2003. Protecting the ozone layer: science and strategy. Oxford University Press, Oxford, UK.

Peterson, D. L., and V. T. Parker, editors. 1998. Ecological scale: theory and applications. Columbia University Press, New York, New York, USA.
Pyne, S. J. 1997. Fire in America: a cultural history of wildland and rural fire. University of Washington Press, Seattle, Washington, USA.

Robinson, J. 2004. Squaring the circle? Some thoughts on the idea of sustainable development. Ecological Economics 48:369-384.

Sabatier, P. A. 1999a. The need for better theories. Pages 3-17 in P. A. Sabatier, editor. Theories of the policy process: theoretical lenses on public policy. Westview Press, Boulder, Colorado, USA.

Sabatier, P. A. 1999b. Fostering the development of policy theory. Pages 261-275 in P. A. Sabatier, editor. Theories of the policy process: theoretical lenses on public policy. Westview Press, Boulder, Colorado, USA.

Sabatier, P. A., and H. C. Jenkins-Smith. 1999. The advocacy coalition framework: an assessment. Pages 117-166 in P. A. Sabatier, editor. Theories of the policy process: theoretical lenses on public policy. Westview Press, Boulder, Colorado, USA.

Salthe, S. N. 1985. Evolving hierarchical systems: their structure and representation. MIT Press, Cambridge, Massachussetts, USA.

Salthe, S. N. 1993. Development and evolution: complexity and change in biology. MIT Press, Cambridge, Massachussetts, USA.

Schlager, E., and E. Ostrom. 1992. Property-rights regimes and natural resources. Land Economics $\mathbf{6 8}$ (3):249-262.

Sen, A., and B. Williams, editors. 1982. Utilitarianism and beyond. Cambridge University Press, Cambridge, UK.

Schiff, A. L. 1962. Fire and water: scientific heresy in the Forest Service. Harvard University Press, Cambridge, Massachussetts, USA.

Sober, E., and D.S. Wilson. 1998. Unto others: the evolution and psychology of unselfish behavior. Harvard University Press, Cambridge, Massachussetts, USA.

Stephan, A. 1992. Emergence-a systematic view on its historical facets. Pages $25-48$ in A. Beckermann, H. Flohr, and J. Kim, editors. 
Emergence or reduction? Essays on the prospects of nonreductive physicalism. Walter de Gruyter, New York, New York, USA.

Stewart, O. C. 2002. The effects of burning of grasslands and forests by aboriginals the world over. Pages 65-338 in H. T. Lewis and M. K. Anderson, editors. Forgotten fires: Native Americans and the transient wilderness. University of Oklahoma Press, Norman, Oklahoma, USA.

Stiglitz, J. E. 2002. Information and the change in paradigm in economics. American Economic Review 92(3):460-501.

Tooby, J., and L. Cosmides. 1992. The psychological foundations of culture. Pages 19-136 in J. H. Barkow, L. Cosmides, and J. Tooby, editors. The adapted mind: evolutionary psychology and the generation of culture. Oxford University Press, Oxford, UK.

Trosper, R. L. 2002. Northwest coast indigenous institutions that supported resilience and sustainability. Ecological Economics 41:329-344.

Trosper, R. L. 2003a. Policy transformations in the US forestry sector, 1970-2000: implications for sustainable use and resilience. Pages 328-351 in F. Berkes, J. Colding, and C. Folke, editors. Navigating social-ecological systems: building resilience for complexity and change. University of Cambridge Press, Cambridge, UK.

Trosper, R. L. 2003b. Resilience in pre-contact Pacific Northwest social ecological systems. Conservation Ecology 7(3):6. (Online.) URL:

http://www.ecologyandsociety.org/vol7/iss3/art6/.

Trosper, T. H. No date. Interview regarding Clearwater National Forest forest fire management.

Vale, T. R., editor. 2002. Fire, native peoples, and the natural landscape. Island Press, Washington, D. C., USA.

Walters, C. J. 1997. Challenges in adaptive management of riparian and coastal ecosystems. Conservation Ecology 1(2): 1. (Online.) URL:

http://www.ecologyandsociety.org/vol1/iss2/art1/.

Weissman, D. 2000. A social ontology. Yale University of Press, New Haven, Connecticut, USA.
World Commission on Environment and Development. 1987. Our common future. Oxford University Press, Oxford, UK. 